\title{
Logics of Local Actors and Global Agents: Divergent Values, Divergent World Views
}

\begin{abstract}
Purpose - In this paper we develop a theoretical explanation of conflicts and incompatible interpretations of events between agents of Multinational Corporations (MNCs) and actors present in certain host countries. We situate the argument in comparative economic systems as a part of a broader social system. The socio-economic system can be modeled using institutional theory, particularly using Scott's (2001) three pillars and the concept of formal and informal institutions. Within different socioeconomic systems a dominant logic is developed, and this becomes internalized among actors and agents as behavioral scripts.
\end{abstract}

Design/methodology/approach - We use a multi-level and multi-disciplinary conceptual analysis, developing a model of dominant logic and behavioral scripts with MNC agents and traditional emerging economy actors.

Findings - MNC agents and traditional emerging economy actors have difficulty comprehending the logic of the other, creating a fertile context for conflict.

Research implications - An ideal type template is developed that can be used for empirical investigations focusing on situations where disagreement and conflict occur when MNCs operate in traditional emerging economies.

Practical implications - By integrating our conceptualization into training for expatriate managers, the potential for conflict can be reduced.

Originality/value - This multi-level and multi-disciplinary model allows grounded development of our understanding of conflicts or potential conflicts in the MNC agent traditional emerging economy actor context.

Keywords - MNC agents, traditional emerging economy actors, dominant logic, comparative economic systems, behavioral scripts, institutions

Paper type - Position paper (viewpoint) 


\section{Logics of Local Actors and Global Agents: Divergent Values, Divergent World Views}

In 2000, Cochabamba, Bolivia was the epicenter of unprecedented social unrest known as the "Cochabamba Water Wars," due to the privatization of the municipal water supply. The conflict drew international attention as a result of several factors. First, it created a state of emergency in Bolivia, which led to food shortages, stranded passengers, and blocked access to main roads. Second, it involved several important agents and actors, including the Bolivian government, local activists, and agents of several multinational corporations and organizations. Specifically, a subsidiary of USbased Bechtel was granted the privatization of Cochabamba's water in a transaction supported by the World Bank. This led to water becoming an economic commodity, rather than a freely consumable resource, like air (Olivera, 2004). Essentially, the local traditional logic of access to the natural supply of water was fundamentally different from the global economic logic of allocating water as a scarce resource. Ultimately Bechtel was forced to withdraw (Spence \& Shenkin, 2008; Birke \& Bohm, 2006).

In 2011 Anglo-Austrian mining giant Rio-Tinto was facing a challenge to hold on to its remaining property in Guinea, after having lost half of its original mining concession in 2008. The newly elected president of Guinea, Alpha Condé, has indicated that existing contracts with Rio-Tinto had not yielded much benefit for his country, and would be voided, while Rio-Tinto blamed the government of Guinea for being slow to process necessary paperwork, preventing the development of the mines. After a meeting between Rio-Tinto CEO, Tom Albanese and Guinea Minister of Mining Mohamed Lamine Fofana the interpretations of the resolution of the issues were quite different. Rio-Tinto says the meeting was "a time for congratulations, rather than talking detailed business," while Minister Fofana says, "the government will not come back to the 2008 decision (to expropriate half of the original mining concession)" (Gauthier-Villars, 2011). 


\section{Introduction}

Were the strategies used by Bechtel or Rio-Tinto adequate given the reactions experienced in Bolivia or Guinea? These events are not unique in the landscape of multinational corporations (MNCs) operating in foreign countries. In fact, most MNCs experience international interactions that range from munificence to unease, which may result in conflict. While the former is desirable, the latter can be very costly, economically, politically, and socially to the firm and country actors alike.

Extant international management literature has come a long way in improving our understanding of interactions between MNCs and their host countries. However, the rapidly and dynamically changing global context requires scholars to reflect on how existing theories explain recent and current reality. Gilpin $(2000,2001)$ argues the twenty-first century will find economic relations ever more filled with conflict due to rival objectives of various MNCs, nations, economic classes and powerful groups. In the emerging or developing countries evidence of such conflicts can be found in resource-intensive regions, where MNCs seek access to valuable assets, such as precious metals, minerals, oil, and labor and are often faced with protests from local populations and anti-globalization groups. We develop a theoretical framework to unpack the conundrums and riddles faced by MNCs from advanced market economies that operate globally in socio-economic contexts different from their own.

Economic activity does not occur in a vacuum, but rather is nested in patterns of economic and social relationships (Dacin, Ventresca \& Beal, 1999). Different countries, regions of countries or transnational regions have patterns of social relationships that coalesce around certain values or traditions (Hofstede, 1980; Vinken, Soeters \& Ester, 2004). These traditions are not simply a vestige of a primeval past, but rather, they represent an important force guiding the economic, political, and social functioning of these countries. We focus on the actions and strategies of MNCs from advanced market economies operating in emerging economies or regions, particularly those that have a strong history of socioeconomic interactions based on tradition. We justify this choice by the desire to obtain more distance between actors, which, in turn, allows us to observe clusters of behaviors and actor attributes more clearly. We acknowledge inherent 
limitations in this approach. Our objective is not to develop a rigid schema of country classifications and characteristics, but rather to develop a theoretical framework helpful in understanding the differences in the two logics.

We frame our discussion in five related areas: (1) institutions, (2) comparative economic systems, (3) actors and agents, (4) dominant logic and (5) behavioral scripts. All economic systems are embedded in a social context. These social contexts and characteristics of each economic system can be mapped and understood using institutional theory. At the social level this institutionalized understanding of the socioeconomic interactions becomes a dominant logic, and at the individual level this dominant logic becomes part of daily life and deciphering of events through behavioral scripts.

This discussion is particularly relevant in relation to tradition based emerging economies. Scholarly management literature over the past thirty years has focused on international business from the perspective of MNCs from one particular socioeconomic context having operations in another socioeconomic context in three ways: (1) operating in a region similar to that of the MNCs' home country, (2) making minor modifications of the MNC core strategy to adapt to the host country, or (3) using the MNC's economic power to shape and exploit the opportunities in the host country (see, for example, Dunning, 1980; Ghoshal, 1987; Buckley, 1988; Hennart, 2001; Rugman \& Verbeke, 2003). While this literature has been a useful reflection of the MNC context, it is incomplete today, particularly for operations in tradition-based emerging economies. In the present context, the world is experiencing a new balance between emerging economies and the advanced market economies of the late twentieth century. Over the past five years the compound annual growth rate has been $11.2 \%$ for China and $8.6 \%$ for India, but only $0.9 \%$ for the United States (Index of Economic Freedom, 2012). The International Monetary Fund estimates the emerging economies will grow at an annual rate of 5.4\% in 2012 and 5.9\% in 2013, while the advanced market economies will grow at a $1.2 \%$ rate in 2012 and 1.9\% in 2013 (IMF 2012: 2) Most of the net growth in employment and consumption will occur in the emerging economies over the next five years, and available natural resources in the advanced economies have been largely depleted, increasing dependence on the emerging economies (Hilsenrath \& Cordeiro, 
2011). These dramatic changes suggest a necessity to reconceptualize the nature of the relationships between MNCs and emerging economies.

\section{The frame of the argument}

We organize extant literature around several key mechanisms, which provide different levers to understand the MNC-host country dynamics and allow us to navigate through multiple levels of analysis in a logical manner. Accordingly, we frame our discussion in five related areas: (1) institutions, (2) comparative economic systems, (3) actors and agents, (4) dominant logic and (5) behavioral scripts.

\subsection{Institutions}

Institutions are understood here as those "supraorganizational patterns of human activity by which individuals and organizations produce and reproduce their material subsistence and organize time and space. They are also symbolic systems, ways of ordering reality, and thereby rendering experience of time and space meaningful" (Friedland \& Alford, 1991: 243). Institutions can be formally constructed and governed or informal and intuitive. Scott (2001) offers the following important characteristics of institutions: (1) Institutions are social structures that have attained a high degree of resilience; (2) Institutions are composed of culture-cognitive, normative, and regulative elements that, together with associated activities and resources, provide stability and meaning to social life; (3) Institutions are transmitted by various types of carriers, including symbolic systems, relational systems, routines, and artifacts; (4) Institutions operate at multiple levels of jurisdiction, from the world system to localized interpersonal relationships; (5) Institutions, by definition, connote stability but are subject to change processes, both incremental and discontinuous.

\subsection{Comparative economic systems}

Economic systems have been defined as a "set of methods and standards by which a society decides and organizes the allocation of limited economic resources to satisfy unlimited human wants; how a society goes about transforming the natural world into material goods" (Conkin, 1991: 1). Dozens of variations of economic systems have been 
identified, some are very familiar to today's scholars of international business, including capitalism, socialism, Islamic, libertarian, mercantilism, feudalism, traditional, market, planned, command or indicative. Others are less familiar, such as syndicalism, progressive utilization, hydraulic despotism, or anarcho-communism (Gardner, 1988; Stuart \& Gregory, 2003). An economic system is embedded in a social/cultural milieu and reflects the values of that society. Both the economic system and social system can be mapped using Scott's three institutional pillars (culture-cognitive, normative, and regulative) and these institutions can be formalized/documented or informal/intuitive.

We contrast two economic systems: the advanced market economic model and the traditional economies as defined by Polanyi (2002) and found in many pre-industrial emerging societies today. Advanced infrastructure, a highly educated workforce, stable democratic governments, and a high per capita Gross Domestic Product (GDP) characterize the advanced market economies. The tradition based emerging economies are characterized by evolving technology, underdeveloped infrastructure, a heavy reliance on non-governmental forms of social structuration and control, and a weak or inefficient market system (Polanyi, 2002).

We focus on contrasting the context of the advanced market economies with that of the traditional emerging economies for two reasons. First, most MNCs originated in and have grown to be global players within the advanced market economies. Emerging country MNCs are growing, but they still make up only a fraction of the global economic activity (Gammeltoft, Pradhan, \& Goldstein, 2010). Second, MNCs are increasingly drawn to traditional economies because the $\mathrm{MNC}$ home markets are experiencing resource depletion, high production costs and stagnating consumption. Alternatives to these are available in the traditional emerging economies. Third, the MNCs of advanced market economies have resource abundance in financial capital, knowledge and proprietary information. MNCs are searching for places where they can put these resources to work and create new growth opportunities.

We acknowledge limitations in this choice of context, but still consider it optimal in our quest to develop clear archetypes that facilitate grasping the core argument. We prefer not to identify particular countries, as the core of the argument is not about countries, but rather about different logics. It is undeniable that parts of China and India 
are rapidly moving toward the global economic logic. But there remain regions of China and India that are heavily grounded in a local traditional logic. We seek to develop an awareness that different logics exist, not that these logics are differentiated on the basis of a particular institutionally defined geographic border. The international setting serves as potential empirical context that illustrates these dynamics more clearly.

\subsection{Actors and Agents}

On the playing field of the various economic systems indicated above, interactions occur between agents and actors. In this analysis we use the concept of agents and actors as developed by Sorge (2005). Within that framework, actors function through spontaneous action systems based on social tradition, while agents function deliberately within an institutionally defined process. At the very basis of this distinction we see actors and agents having different perceptions of reality, where the actor's reality is based on social and cultural tradition, while the agent's reality is based on a global economic system (Djelic, 1998). Furthermore, agents appear as proactive economic opportunity seekers, while actors are motivated primarily by the desire to preserve a way of life. The concept of tradition allows for actors to express concern for economics, as means to an end, but not as primary purpose. In this conceptualization, we see actors as unbound by the same institutional frameworks or constraints as the agents.

Sorge's work describes the process by which actors and agents come to mutual accommodation through a layering process over time. We support Sorge's conceptualization. Our argument is focused on the initial meeting of the two logics. We acknowledge that local traditional based economies are moving toward a postmodern world, but this does not happen instantaneously or seamlessly.

We use the term actor to define individuals acting within the local tradition based community. Agents are individuals who act representing the Multinational Corporation. Both actors and agents are shaped by their socio-cultural environment, within which an economic system is situated. Agents who are native to the tradition-based emerging economy may experience conflict, or alternatively may have experienced extensive socialization into the milieu of the MNC such that they can compartmentalize their native socialization from their corporate socialization. 


\subsection{Dominant Logic}

Dominant logic is "the way in which (individuals) conceptualize and make critical... decisions" (Prahalad \& Bettis, 1986:490). It is a subtle understanding of the way the world works. MNC agents or local actors internalize it through schemas, mindsets and cognitive maps. Agents or actors interpret information received from the external environment, filtering it in such a way that data that is inconsistent with their dominant logic is ignored, while data that is supportive of the dominant logic is given more weight than it might warrant. Dominant logic is a subtle but real force that "predisposes one to certain problems and interacts with organizational structure and systems in causing strategic problems" (Bettis \& Prahalad, 1995:9).

Dominant logics come into play by establishing a cognitive mindset within individuals that is consistent with the actor's or agent's history and culture. It allows agents and actors to develop heuristics that facilitate rapid decision-making. In a stable equilibrium environment this logic can be useful and favorably routinized. It can also become part of the set of competencies, which distinguish a firm from its competitors or a local community or region from its neighbors. However, in a turbulent and nonequilibrium environment, the dominant logic can be an impediment to successful adaptation.

The discussion of dominant logics is relevant here because it leads actors and agents to formulate strategies and make decisions in a routinized and preconscious manner - one that reflects the dominant logic of their environment (Oliver, 1997). This suggests the very distinct likelihood that decisions consistently embed the schemas of one logic or another. To illustrate, the dominant logic of the MNC agent from the advanced market economy emphasizes effectiveness and efficiency, areas where the MNC excels, and for which the global market rewards it. However, when these values are transferred to traditional emerging countries, the actions resulting from these logics may be interpreted as illegitimate or inappropriate (Maclean \& Hollinshead, 2011).

Because the dominant logics of the MNC agents and the local actors are selfreferential and emanate from significantly different contexts, direct communication between the two is difficult; the same words, observations and observable reality can 
have different meanings to the MNC agents and the local actors (Seidl, 2007). It is this different interpretation of what is legitimate and appropriate that can cause difficulties, because a lack of understanding of each party's logic can lead to significant misunderstandings or conflict, as illustrated by the two vignettes we provide at the outset.

\subsection{Behavioral scripts}

For a dominant logic to impact the interactions between MNC agents and local actors, each must have a respective collective conscience that is internalized at the cognitive level (Scott, 1992). These behavioral scripts are in the form of deeply embedded templates that are taken for granted and unconsciously enacted (Johnson, Smith \& Codling, 2000) in making routine or strategic decisions. These behavioral scripts are a product of the context within which the agent or actor has become socialized into his or her environment. Such scripts are the personal internalization of the society's culture, taken for granted norms and acceptable patterns of worldview. These deeply ingrained scripts often prevent an actor or agent from comprehending the possibility of other behavioral scripts, or if they are grasped, the alternatives are often seen as illegitimate, irrational or irrelevant, because they are not built on systematically similar core cultural tenets (Özkazanc-Pan, 2008).

Our argument, therefore, rests upon an understanding that MNC agents and host country actors act upon different behavioral scripts, which reflect the dominant logic of their environment. This results in observable unease, where, from the perspective of the global economic logic, the local traditional logic is perceived as being irrational or quaint, while from the local traditional logic the global economic logic is perceived as cold, calculating and lacking in human sensitivity (Özkazanc-Pan, 2008).

So far, we described five mechanisms, which delineate the interaction between agents and actors, across multiple levels of analysis and stages of abstraction. We build on these moving forward and develop an ideal type framework to describe two archetypes. Such typologies form a theoretical framework useful in developing models that can be empirically investigated (Doty \& Glick, 1994).

\section{Different worldviews}


3.1 Why did the Bechtel agents and the Cochabamba actors view water so differently? Why did the Rio Tinto CEO view the outcome of a meeting with the Guinean Minister of Mines so differently? Why do MNCs continue to experience resistance as they expand operations into emerging countries? In this section we utilize our framing elements to explore why these conflicts and misunderstandings can occur.

\subsection{Define two logics}

To find common ground in our analysis of this relationship, we examine two different dominant logics. The first logic is that of the MNCs from the advanced market economies, and we title this global economic logic. We propose that MNCs from the advanced market economies act on the basis of economic rationality and their managers are mentally motivated and guided by the identity referents and the cultural environment specific to the advanced market economies where these organizations evolved. This rationality is founded on an economic legitimacy. It is based on a strategic process of mobilization of specialized resources guided by an orientation toward efficiency (Djelic, 1998). This economic design is well described in management, through the work of Porter (1979) on competition, of Williamson (1979) on transaction costs and Barney (1997) on resources. It is largely an abstract intellectual epistemology. Managers of MNCs from the advanced market economies generally adopt strategies strongly determined by this rationality.

The logic of MNC success being based on economic and financial performance has become a cognitive assumption among executives and scholars; the underlying reasonableness is not often questioned. This focus on economic efficiency and effectiveness is the accepted and rational approach for understanding MNC strategy, actions and performance. It is grounded in assumptions of bounded rationality, goal specificity and formalization. We acknowledge a growing interest in the related areas of corporate social responsibility and corporate sustainability, which expand the meaning of firm performance by including metrics relative to the natural and social environments. Much of that literature perpetuates the economic logic, by providing firms with tools that allow them to find new opportunities for efficiency or growth. The continued use of 
economic logic in MNCs leads to dynamic decision processes that are necessary to attain high levels of efficiency, effectiveness and financial performance. Management development programs, promotion decisions and strategic processes in MNCs are all aligned with these economic goals.

The other logic relates to the behavior and strategies developed by actors in emerging countries and we title this local traditional logic. Such behavior and strategies reflect local traditions and values, which often emphasize community, clan or sharing. This is due not only to cultural referents (Adler, 1997) specific to these countries, but also to the institutional frameworks in which strategies are developed. These are founded on a traditional legitimacy, in which the dominant rationality rests more on the communitybased and clan-like social bonds than on economic performance (Inda \& Rosaldo, 2002).

The local traditional logic reflects a radically different cultural environment than that of predominantly market-based economies. Emerging economies, especially those with a strong tradition referent, often have institutional instability, informal constraints on decision-making, a non-monetary exchange system, and a great emphasis on tradition, heritage, family, clan and informal rules and norms (Hoskisson et al. 2000; Khanna \& Palepu, 1997; Peng \& Heath, 1996). When compared with advanced market economies, tradition based emerging countries have a different macroeconomic base from which to work and a non-codified institutional framework constraining decisions.

The presence of different logics is not unique to the economic logic of MNCs and more traditional social economies, although we are emphasizing this pairing. Maclean and Hollinshead (2011) found evidence of conflicting logics when the Turkish MNC Eden acquired the Serbian brewer Weisser. Clear evidence was present of the MNC actors' viewing the world through a global economic logic, which conflicted with the local Serbian agents more traditional local logic.

\subsection{Characteristics of the two logics}

What might be some of the characteristics of the global economic logic and the local traditional logic? When using our approach to the analysis of global-local logics, the complexity in the relations between agents of the $\mathrm{MNC}$ and the actors in the tradition based economy become central. Each has a different way of seeing the world, and each 
operates according to different rationalities. The cognitive and cultural elements, as well as the normative and regulating aspects of institutions, determine the rules, standards and cultural values, which, in turn, shape the ways of thinking and behavior (Inda \& Rosaldo, 2002). The normative standards in emerging countries are based primarily in culture, history or community (Miller, 1995) while the normative standard in advanced market economies is more focused on issues of cost-effectiveness, efficiency and financial performance (Djelic, 1998). Each institutional environment will shape and evolve through multiple unique and legitimate rationalities (Scott, 2001). The institutional processes set the parameters of what is agreed upon as being rational or logical within a given social framework.

The advanced market economies function with a more rational, and less communal or traditional sense of decision-making. Rational theories are built around goal specificity and formalization and are integrated into the concept of bounded rationality (Scott, 1992). The local institutional environment and cultural dimensions of traditional emerging economies can call into question assumptions of goal specificity, formalization and boundedly rational decision processes (Hafsi \& Gauthier, 2003). Traditional emerging economies display less stable and formal political, regulatory, and economic institutions, while informal local institutions have power and are important for decision making within organizations. Managerial ties are more central in business relationships in environments with a higher level of uncertainty (Pfeffer \& Salanick 1978; Powell 1990) when formal institutions, such as laws and regulations, are weak, and informal local institutions play a major role in economic activities (Peng \& Heath 1996). A slower and more patient process of mutual discussion and socializing is required in emerging economies to reach agreement (Child 2001).

Table 1 demonstrates and synthesises sample characteristics of the two logics. This table shows the anticipated differences between advanced market economies and local traditional economies, and can be used as the specification for an ideal type methodology (Weber, 1949) for empirical work.

Insert Table 1 about here 
To illustrate, we argue that the advanced market economies are more likely to have individualistic cultures and monetary-based exchange cultures, while the traditional economies are more likely to have communitarian and non-monetary exchange cultures. Morris et al. (1998) showed that in contexts where values and conceptions of purposes are individualistic, dynamism and the use of a competitive management style become essential. Individual rationality is legitimate, and this is reflected in the dominant logic. Lodge and Vogel (1987) showed that in contexts where values and conceptions of purposes are less individualistic and more communitarian, efforts to sustain community and provide for the members of the collective are central; decision processes are less dynamic and 'conformity' will be considered as a value among managers (Schwartz, 1994). Jaeger (1990) argued that in the traditional economies culturally defined limitations constrain the accepted rationality of individuals. A high degree of powerdistance and a high degree of uncertainty avoidance makes decision and authority processes less dynamic in these contexts. Child (2001) built upon this, arguing that in traditional economies local social relationships become more central to defining the dominant logic.

Traditional economies can be generally characterized as having high degrees of environmental uncertainty and turbulence; centralized control of the economic and political systems; relatively weak and unstable legal systems; underdeveloped infrastructure; and lack of developed financial service institutions. For example, in many traditional economies there is a lack of consistency between old and new laws. Moreover, while many traditional economies use French or English civil laws, they retain few procedural aspects, and even fewer updates of these procedures are legislated. As a result, the legal environment of traditional economies is often unsupportive of economic activity, which generally requires swift, uncluttered legal procedures.

As such, a local tradition based country's logic is stressed when confronted with the MNC's global economic logic, particularly when the local economy is dependent on the MNC for economic development. In emerging economies, market-supportive institutions are weak to begin with, based largely on cognitive conceptualizations founded in tradition, untested by economic thought. In these societies values and norms are often transferred from one generation to the next through oral patterns, rather than the 
formalized and rationalized processes of the advanced market economies, such as formal education, regulations, written manuals, textbooks or prescribed processes to uncover the best practices in formulating a decision.

\section{Implications}

We have argued that, when a MNC operates in a local emerging economy environment, its agents carry with them the behavioral script of the advanced market economy (Johnson, Smith, \& Codling, 2000). Given the weak and informal institutional framework in the traditional emerging economy, these MNC agents observe not a conflicted institutional structure, but rather — from the global economic logic script — an empty institutional frame.

Seeing this institutional void, the MNC agents seek to improve the weak institutional structure of the host country. To these agent/managers a stronger formal institutional frame would reflect the value of the advanced market economy, which the agents have internalized in their behavioral script. The agent's efforts are proactive, positive and carried out in the belief that these actions will be beneficial to the emerging economy. But this transition pits traditional local practices and values against rational economic institutional frames. For Bechtel water was a valuable economic resource, but for the Cochabambians water was a gift from mother earth.

The above may paint a picture consistent with observed misunderstandings and conflicts between MNC agents and local actors, and one can argue it offers little beyond a theoretical grounding of what we observe in the daily world. Given the successes of MNCs in efficiently and effectively mobilizing economic resources, why would these corporations want to develop strategies for traditional emerging economies that can achieve corporate objectives that can also acknowledge the value of the local traditional logic? The existing international business literature does not adequately address this question, and our framing of the two logics adds an explanatory variable in unraveling tensions between global agents and local actors. As it now stands, actions by MNC agents can be detrimental to both traditional emerging economy and to the MNC itself for two reasons, grounded in resource dependency theory and conflict theory. 
Resource dependency theory. In the long term, over the next quarter to half century, the resources needed for MNC strategic success will be ever more located in the traditional emerging economies of Africa, the Middle East, South America and Asia. These resources include energy, untapped natural resources and minerals, employees, and increasingly, new markets for products. As the advanced market economies become depleted of energy sources and natural resources, as productivity and wage rates diverge, as more and more jobs are outsourced to low income countries, as more and more American debt is held by China or OPEC countries and as the huge and rapidly growing populations of the emerging countries are able to afford more and more consumer goods and industrial products, the advanced market economy MNCs will become ever more dependent on emerging economies to achieve corporate objectives. Applying resource dependency theory, firms will act in self-interest, trying to gain access to, and ultimately control over, needed resources (Pfeffer \& Salancik, 1978); MNCs attempt to minimize dependencies on others for required resources while simultaneously making others dependent on the MNC for products or employment. In the context of the scenario developed above, the MNC strategy in emerging economies will be to control the resources located in those countries, and seek to make emerging economies dependent on the MNC to achieve the national objectives for their people, whether they are social, cultural or economic in nature.

We have no doubt the MNCs can achieve this, and will do so in the short term. But it will come at an ever-increasing price, if the underlying global economic logic becomes more and more overbearing on the local traditional logic. There will be a growing dependency of the MNC on the resources and markets of the emerging countries, a growing dependence of the emerging countries on the MNCs efficiently and effectively mobilizing these resources for both the benefit of the emerging country and the MNC itself. Some argue these conflicting logics can mutually evolve into ever more complex webs and layers of institutional frames and that the conflict need not erupt.

We hope this is correct, but given what we observe in the world today we are not optimistic, primarily because we believe that strategic decision makers in advanced market economy MNCs are largely unaware of their internalized behavioral scripts and taken for granted global economic logic. If these strategic decision makers remain 
unaware of their internalized scripts and rationalities, the increased mutual dependency of the MNCs and traditional emerging countries may lead to more and more misunderstanding and eventually increased conflict.

Conflict theory. The underlying premise of conflict theory is that societies and organizations struggle to maximize their own objectives and benefits (Collins, 1975). Each society and organization will compete to control the scarce resources required to achieve its particular objectives. Under conflict theory the dispute resolution mechanism is competition, not consensus or compromise. Conflict is more volatile when there is structural inequality in terms of power distribution or reward (Dutta \& Mishra, 2005). If a weaker player perceives the stronger player enjoying significantly unequal distribution of resources or rewards, the weaker player will eventually attack the stronger player, even if this appears to the strong player to be irrational. In 2006 ten percent of the world's population controlled for $85 \%$ of the world's wealth, while the bottom half of the world population owned barely one percent of global wealth (Davies, Sandstrom \& Wolff, 2006) This may lead to conflict, which is destructive of the resources on which both the advanced market economy MNCs and the populations of the emerging economies depend. There is sufficient evidence to support this claim, ranging from peaceful protests to aggressive acts of terrorism directed at individuals, organizations and advanced market countries.

\section{Conclusions}

Dacin, Ventresca, and Beal (1999) remind us that economic activity does not occur in a vacuum, but rather is nested in patterns of economic and social relationships. This is the key to the uneasy interaction between global and local forces: global economic logic is enacted as strategies of MNCs embedded in the patterns of economic and social relationships of the advanced market economies, while the local traditional logic is embedded in the incremental patterns of social relationships of the traditional emerging economies. These institutional frames are different, and often inconsistent (Farashahi \& Molz, 2004).

Further research: We present this as a viewpoint paper, and we hope empirical research can be carried out to verify, modify, enhance or refute our conceptualization, using our 
model as an ideal type template. Research could be done using secondary data and event studies of failed MNC - local traditional economy interactions, mapping out the sequence of interactions and applying the ideal type to sort the data (Doty \& Glick, 1994). Alternatively, rich case studies can be developed through fieldwork directly immersing the researcher in the milieu of a brewing conflict between a MNC and its host community. This requires researchers to immerse themselves in the unique environment of the MNC agent - local actor interaction, and using the relevant points of tension to understand the seeds of disagreement. Both approaches would add value to better understanding the emergence of MNC local conflict.

We offer a final question to stimulate further debate on this topic, inspired by the viewpoints presented in this article. Drawing on the institutional theory, are isomorphic/hegemonic pressures preventing or inhibiting academic researchers, expatriate managers, and corporate strategists from searching out new perspectives on MNCs in developing countries? This question prompts a self-reflection on the dominant logic and behavioral scripts used by individuals in managerial decision-making. Summing up: Our two brief examples of Bechtel and Rio Tinto have called attention to situations where the agents of a MNC misunderstand the local realities in a traditional emerging economy, leading to failure. Our contribution is to provoke debate among scholars over why MNCs experience uneasy or conflictual relations in traditional emerging economies. We further suggest that an ambidextrous knowledge and use of these logics is a possible avenue to reconciling relationships, and developing more munificent relationships.

We present this Viewpoint Paper to stimulate debate, grounded in our observations but situated within an academic model. First, we frame our analysis in comparative economic systems, grounding the argument in institutional theory. Second, we extend this by introducing an examination of process, using concepts of dominant logic, behavioral scripts and differentiating each of these for $\mathrm{MNC}$ agents and actors representing local traditional values. Third, this framework can be tested empirically using an ideal type research protocol (Weber, 1949). Fourth, we propose the resource dependency and conflict theories to strengthen the argument that an organization benefits from the adoption of strategies that encourages agents to be open to understanding and 
learning the underlying logic of the host country. This point is critical both for theory and for practice, as businesses engage increasingly in international activities, and in doing so, they increase the frequency of interactions with, and potential impact on local firms, communities, and institutions.

We argue that there are important reasons why MNCs would gain from understanding the logic of actors from developing economies, while continuing a global economic logic. Further, we suggest that MNCs' activities will be ever more dependent on resources from traditional economies and their awareness and integration of the local traditional logic will be mutually beneficial. In an environment where countries are increasingly imposing pressures on corporations, MNCs' ability to create close relationships in local developing economies can positively impact MNCs' survival and performance in those countries. 


\section{REFERENCES}

Adler, N. (1997), International dimensions of organizational behaviour, South-Western College Publishing, Ohio.

Barney, J. B. (1997), Gaining and sustaining competitive advantage, Addison Wesley, Reading, Mass.

Bettis, R. A., \& Prahalad, C. K. (1995), "The dominant logic: Retrospective and extension", Strategic Management Journal, Vol. 16 No. 1, pp. 5-14.

Birke, O. \& Bohm, S. (2006), "The people and resistance against international business: The case of the Bolivian "water war". Critical Perspectives on International Business, Vol 2 No 4, pp.299-320.

Buckley Peter J. (1988), “The limits of explanation: Testing the internalization theory of the multinational enterprise". Journal of International Business Studies. Vol. 19 No. 2 , pp. 181-193.

Child, J. (2001), "Trust - The fundamental Bond in Global Collaboration", Organizational Dynamics, Vol. 29 No. 4, pp. 274-288.

Collins, R. (1975), Conflict Sociology, Academic Press, New York.

Conklin, D. (1991), Comparative Economic Systems, University of Calgary. Press, Calgary.

Dacin, M. T., Ventresca, M. J., \& Beal, B. D. (1999), "The embeddedness of organizations: Dialogue \& directions", Journal of Management, Vol. 25 No. 3, pp. 317356.

Davies, J., Sandstrom, S. \& Wolff, E. (2006) The World Distribution of Household Wealth. United Nations University, World Institute for Developmental Economics Research. Press Release 5 December 2006. (PFDF wider-wdhw-press-release-5-12-2006)

Djelic, M. L. (1998), "Exporting the American model: The postwar transformation of European business", Oxford University Press, New York.

Doty, D, H., \& Glick, W. H. (1994), “Typologies as a unique form of theory building: Toward improved understanding and modeling", Academy of Management Review, Vol.19, pp. 230-251.

Dunning, J. H. (1980), “Toward an Eclectic Theory of International Production: Some Empirical Tests”, Journal of International Business Studies, Vol. 11 No. 1, pp. 9-31.

Dutta, I \& Mishra, A. (2005), “Does Inequality Lead to Conflict?”, United Nations University, World Institute for Developmental Economics Research, Research paper 2005/34. 
Farashahi, M., \& Molz, R. (2004), “A framework for multilevel organizational analysis in developing countries", International Journal of Commerce and Management, Vol. 14 No.1, pp. 59-78.

Friedland, R., \& Alford, R. (1991), "Bringing society back in: Symbols, practices, and institutional contradictions", In W. W. Powell, \& P. J. DiMaggio (Eds.), The New Institutionalism in Organizational Analysis, The University of Chicago Press, Chicago, London, pp. 232-263

Gammeltoft, P., Pradhan, J.P., \& Goldstein, A. (2010), "Emerging multinationals: home and host country determinants and outcomes", International Journal of Emerging Markets, Vol. 5, pp.254-265.

Gardner, H. (1988), Comparative Economic Systems, Holt, Rinehart and Winston, New York.

Gauthier-Villars, D. (2011), "Mining Fight Shows Pressures on Multinationals", Wall Street Journal, Business, page 1.

Ghoshal, S. (1987), “Global strategies: An organizing framework", Strategic Management Journal, Vol. 8, pp. 425-440.

Gilpin, R (2000), "The Challenge of Global Capitalism : The World Economy in the 21 st Century” Princeton University Press, Princeton, NJ.

Gilpin, R (2001), "Understanding the international economic order" Princeton University Press, Princeton, NJ.

Hafsi, T., \& Gauthier, B. (2003), "Environment, strategy, and leadership patterns as determinant of firm performance: A study of Cameroonian firms", Cahier de la Chaire de management stratégique international Walter-J.-Somers, September 2003(\#25-01).

Hennart, J.-F. (2001), “Theories of the Multinational Enterprise”, In A. Rugman and T. Brewer (eds.), The Oxford Handbook of International Business, Oxford University Press: Oxford, UK, Chapter 5, pp.: 127-149.

Hilsenrath, J. \& A. Cordeiro, A. (2011), "Uneven Global Growth Bedevils CEOs”, Wall Street Journal, January 26, 2011, page A1.

Hofstede, G. (1980), Culture's consequences, Sage, Beverly Hills.

Hoskisson, R., Eden, L., Lau, C., \& Wright, M. (2000), "Strategy in emerging economies", The Academy of Management Journal, Vol. 43 No. 3, pp. 249-267.

Inda, J., \& Rosaldo, R. (2002), “Introduction: A World in motion”, The Anthropology of Globalization, Blackwell Publishing, Walden, Ma, pp. 1-34. 
Index of Economic Freedom (2012), Heritage foundation.

www.heritage.org/index/country/china, www.heritage.org/index/country/india, www.heritage.org/index/country/unitedstates

International Monetary Fund. (2012), "World Economic Outlook Update", Washington, D.C. January 24, 2012.

Jaeger, A. (1990), "The Applicability of Western Management Techniques in Developing Countries: A Cultural Perspective", in Management in Developing Countries, A. Jaeger and R. Kanungo (Eds.), London, Routlege, 1990, pp. 131-145.

Johnson, G., Smith, S., \& Codling, B. (2000), "Microprocesses of institutional change in the context of privatization", Academy of Management Review, Vol. 25 No. 3, pp. 572580 .

Khanna, T., \& Palepu, K. (1997), "Why focused strategies may be wrong for emerging markets", Harvard Business Review, Vol. 75 No. 4, pp. 41-49.

Lodge, G., \& Vogel, E. (1987), "Ideology and national competitiveness", Harvard Business School Press, Boston.

MacLean, M. \& Hollinshead, G. (2011), "Contesting social space in the Balkan region: the social dimensions of a "red" joint venture." In Dörrenbächer, C. \& Geppert, M. (Eds.) Politics and power in the multinational corporation: The role of institutions, interests, and identities, Cambridge University Press, pp. 380-412.

Miller, D. (1995), "Consumption and Commodities", Annual Review of Anthropology, Vol. 24, pp. 141-161.

Morris, M. W., Williams, K. Y., Leung, K., Larrick, R., Mendoza, M. T., Bhatnagar, D., Li, J., Kondo, M., Luo, J.-L., \& Hu, J.-C. (1998), "Conflict management style: Accounting for cross-national differences", Journal of International Business Studies, Vol. 29 No. 4, pp. 729-748.

Oliver, C. (1997), "Sustainable competitive advantage: Combining institutional and resource based views”, Strategic Management Journal, Vol. 18 No. 9, pp. 697-713.

Olivera, O. (2004), Cochbamba!: water war in Bolivia, South End Press, Cambridge, MA.

Özkazanc-Pan, B. (2008), "International management research meets «the rest of the world»", Academy of Management Review, Vol. 33 No. 4, pp. 964-974.

Peng, M. W., \& Heath, P. S. (1996), "The growth of the firm in planned economies in transition: Institutions, organizations, and strategic choice", Academy of Management Review, Vol. 21 No. 2, pp. 492-528. 
Pfeffer, J., \& Salanick, G. R. (1978), The external control of organizations: A resource dependence perspective, Harper and Row, New York.

Polanyi, K. (2002), The Great Transformation: The Political and Economic Origins of Our Time, Beacon Press, Boston, MA (first published 1944).

Porter, M. (1979), "How competitive forces shape strategy", Harvard Business Review, Vol. 57 No. 2, pp. 137-145.

Powell, W. W. (1990), "Neither market nor hierarchy: Network forms of organization", In B. M. Stow, \& L. L. Cummings (Eds.), Research in organizational behavior, Vol. 12, pp. 295-336. Greenwich, CT.: JAI Press.

Prahalad, C. K., \& Bettis, R. A. (1986), "The dominant logic: A new linkage between diversity and performance", Strategic Management Journal, Vol. 7 No. 6, pp. 485-501.

Rugman, A.M. \& Verbeke, A. (2003), "Extending the theory of the multinational enterprise: internalization and strategic management perspectives", Journal of International Business Studies, Vol. 34 No. 2, pp. 125-137.

Schwartz, S. H. (1994), "Beyond individualism/collectivism: New cultural dimensions of values", In U. Kim, H. C. Triandis, C. Kacitcibasi, S. C. Choi, \& G. Yoon (Eds.), Individualism and collectivism: Theory, methods, and applications, Sage, Thousand Oaks, CA, pp. 85-119.

Scott, R. W. (1992), Organizations: Rational, natural, and open systems (3rd ed.), Prentice Hall, Englewood Cliffs, N.J.

Scott, W. R. (2001), Institutions and Organizations, Sage Publications, Thousand Oaks.

Seidl, D. (2007), "General strategy concepts and the ecology of strategy discourses: A systemic-discursive perspective”, Organization Studies, Vol. 28 No. 2, pp. 197-218.

Sorge, A. (2005), The Global and the Local: Understanding the dialectics of business systems, Oxford University Press, New York.

Spence, C. \& Shenin, M. (2008), "The rebirth of politics in Bolivia: the role of popular resistance to business", Critical Perspectives on International Business. Vol. 4, No. 4., pp. 344-366.

Stuart, R. \& P. Gregory (2003). Comparing Economic Systems in the Twenty-First Century, South-Western.

Vinken H., J. Soeters \& P. Ester. Eds. (2004), Comparing cultures: dimensions of culture in a comparative perspective, Leiden Brill, Boston.

Weber, M. (1949), Methodology and the Social Sciences, The Free Press, Glencoe, Il. 
Williamson, O. (1979), "Transaction cost economics: The governance of contractual relations", Journal of Law and Economics, Vol. 22, pp. 233-261. 
TABLE 1

Comparative summary of dominant logics

\begin{tabular}{|c|c|c|}
\hline & $\begin{array}{l}\text { Advanced Market Economy } \\
\text { Global Economic Logic }\end{array}$ & $\begin{array}{l}\text { Tradition Based Emerging } \\
\text { Economy } \\
\text { Local Traditional Logic }\end{array}$ \\
\hline Dominant force & $\begin{array}{l}\text { Economic Conceptualizations } \\
\text { of efficiency, effectiveness and } \\
\text { surplus }\end{array}$ & $\begin{array}{l}\text { Anthropological } \\
\text { conceptualizations of tradition }\end{array}$ \\
\hline Supremacy of & Market & Tradition, community, clan \\
\hline Role of market & To achieve economic objectives & $\begin{array}{l}\text { To obtain goods needed to } \\
\text { sustain life, community, } \\
\text { tradition }\end{array}$ \\
\hline Role of tradition & $\begin{array}{l}\text { To legitimize economic } \\
\text { rationality }\end{array}$ & $\begin{array}{l}\text { Historical bridge to current and } \\
\text { future rationality }\end{array}$ \\
\hline Governance by & Self regulatory markets & Traditional guidance \\
\hline Property rights & $\begin{array}{l}\text { Well defined and organized to } \\
\text { generate economic surplus, } \\
\text { formal institutional structure }\end{array}$ & $\begin{array}{l}\text { Often community based, } \\
\text { organized to sustain human } \\
\text { relationship with tradition, and } \\
\text { clan, informal institutional } \\
\text { structure }\end{array}$ \\
\hline Decision criteria & Economic cost benefit & Respect for tradition \\
\hline $\begin{array}{l}\text { Temporal } \\
\text { considerations }\end{array}$ & $\begin{array}{l}\text { Fast decisions, short to medium } \\
\text { term orientation }\end{array}$ & $\begin{array}{l}\text { Slow decisions, medium to long } \\
\text { term orientation }\end{array}$ \\
\hline Geocentricity & Global & Local \\
\hline Social networks & $\begin{array}{l}\text { Instrumental to achieve } \\
\text { economic objectives }\end{array}$ & Core to clans and community \\
\hline Key philosophers & $\begin{array}{l}\text { Neo-liberalism - Smith, } \\
\text { Friedman }\end{array}$ & $\begin{array}{l}\text { Local dominant philosophies: } \\
\text { Confucianism, Buddhism, Islam, } \\
\text { Christianity, etc. } \\
\text { Polanyi }\end{array}$ \\
\hline Knowledge & Science / Truth / Positivism & $\begin{array}{l}\text { Historical and traditional } \\
\text { wisdom / Interpretive }\end{array}$ \\
\hline Benchmarks & Results, performance & Process, sustainability \\
\hline
\end{tabular}

